POLLACK PERIODICA

An International Journal for Engineering and Information Sciences

DOI: $10.1556 / 606.2016 .11 .3 .2$

Vol. 11, No. 3, pp. 5-14 (2016)

www.akademiai.com

\title{
THE VISUAL WORLD VIEW OF ZOLTÁN BACHMAN
}

\author{
Julianna P. SZÜCS \\ Department of Visual Knowledge, Faculty of Engineering and Information Technology \\ University of Pécs, Boszorkány u. 2, H-7624 Pécs, Hungary \\ e-mail: p.szucs.julianna@mik.pte.hu
}

Received 3 May 2016; accepted 27 September 2016

\begin{abstract}
The paper has been presented at the ceremonial lecture held on 29 April 2016 for the nomination of the main lecture hall in the Science Building after the genius professor Zoltan Bachman belonged to the Faculty of Engineering and Information Technology, University of Pecs.
\end{abstract}

Keywords: Zoltan Bachman the Master, Cella Septichora, Composition of a pilgrim church in Croatia, The Science Building, Graphic art heritage, The workshop

\section{Introduction}

Let me start by explaining my choice of title. For me Zoltán Bachman was the kind of Master (Fig. 1) whose oeuvre cannot be examined in bits and pieces. In the context of his work it does not make sense to specify the number of buildings constructed or projects completed, or to separately examine the university, or workshop or 'the school' as he used to simply put it, from all other aspects of his work. Similarly, there is no use contrasting the different fields of his activity and measuring how much one benefited from the others (Fig. 2). Because there is no one who could reveal the secret motives behind the performance of students, the architectonic roots of the heroes of pastels, the aesthetic and pedagogical furore of sketches and models, or the energies lying behind completed works to which the community, history, innovation and traditions all contribute. 


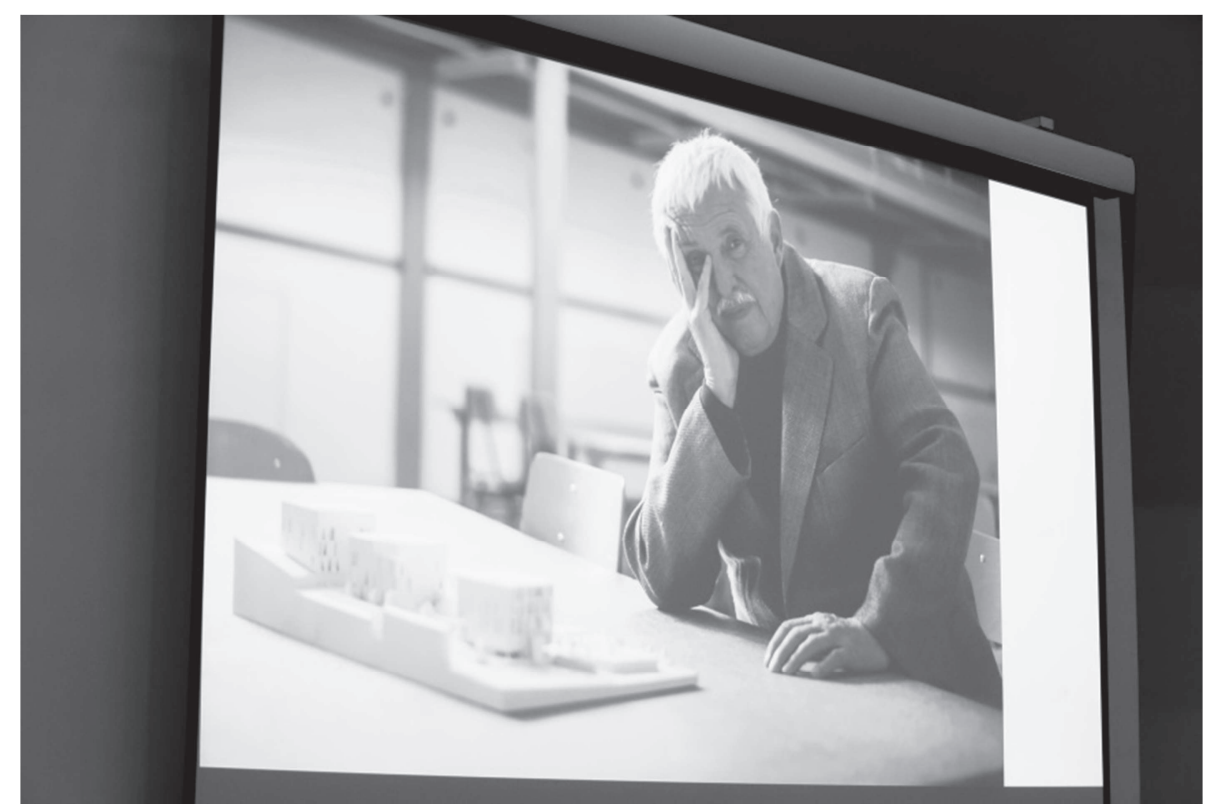

Fig. 1. Professor Bachman Zoltan

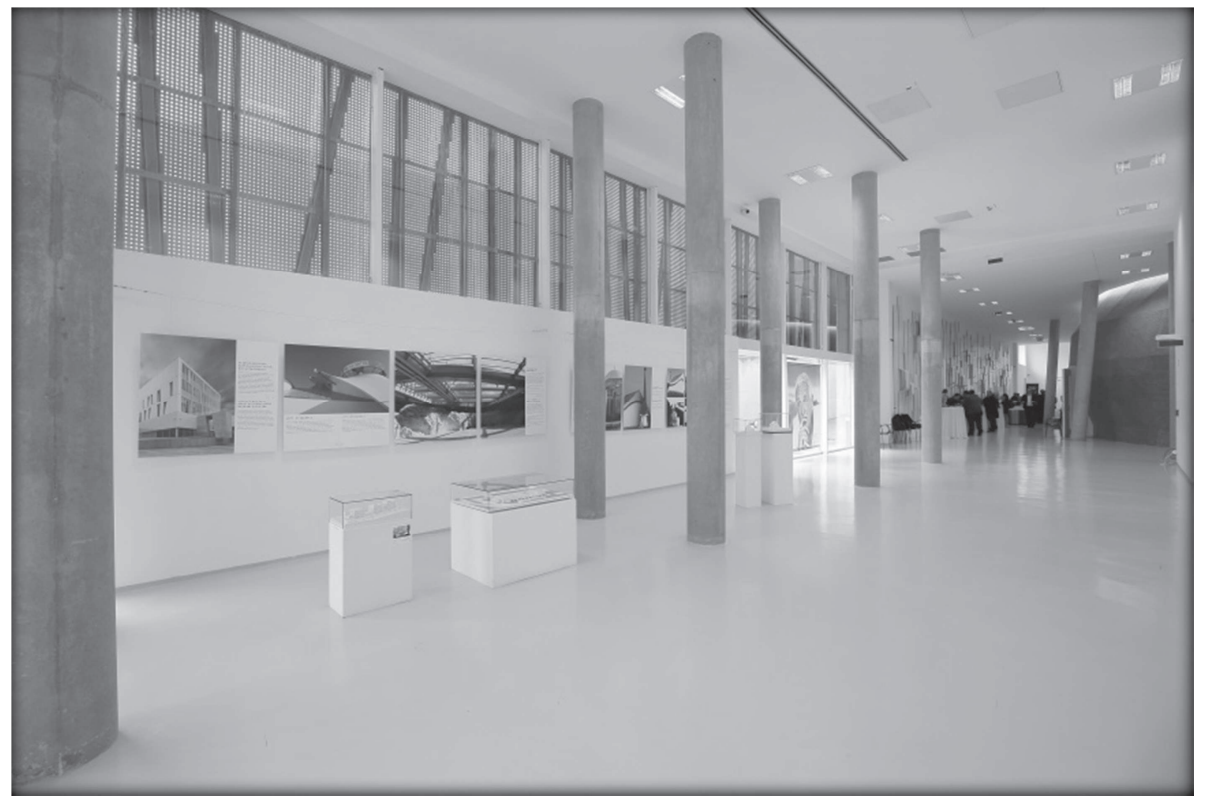

Fig. 2. Zoltan Bachman exhibition in the Science Building

Pollack Periodica 11, 2016, 3 


\section{The genius of the professor}

Taking a look at his oeuvre - his design plans, buildings and works of art -, what strikes one's eyes most is unity. His designs never followed momentary trends although at times he did become fascinated by organic forms or high-tech architecture and his artistic world never aimed to meet the down-to-earth expectations of professional circles sticking perhaps too much to specific stylistic practices - although symbolic expression apparently fitted him better than sterile abstractionism. The sight his works offer is always a manifestation of a fragment of universal knowledge [1].

These works may represent a small piece of the big picture, a memory splinter or to evoke Plato's metaphor - shadows of memory fragments projected on the wall of the cave. For him the world was always a source of excitement, a playfully rich terrain for constant experimentation and an enduring realm of creative work. He never liked making a choice among the many toys surrounding him; he rather enjoyed trying them all. There was however something that actually manifested in the unity of his oeuvre: the great vision, a cohesive rationale, the BIG PICTURE, the realm of the transcendent.

Bachman never denied that this 'big picture' of his oeuvre, as his students would call it, rested upon an ethereal faith imbued with spiritual devotion in the centre of which stood the undepictable Almighty; this faith renders the constantly changing set of stylistic practices of man-made artefacts a consubstantial unity irrespective of all historical changes. His art is truly religious, and a very special, one of a kind art.

The Cella Septichora, an exceptional archaeological find from the ancient city of Pécs, stands as an excellent example (Fig. 3).

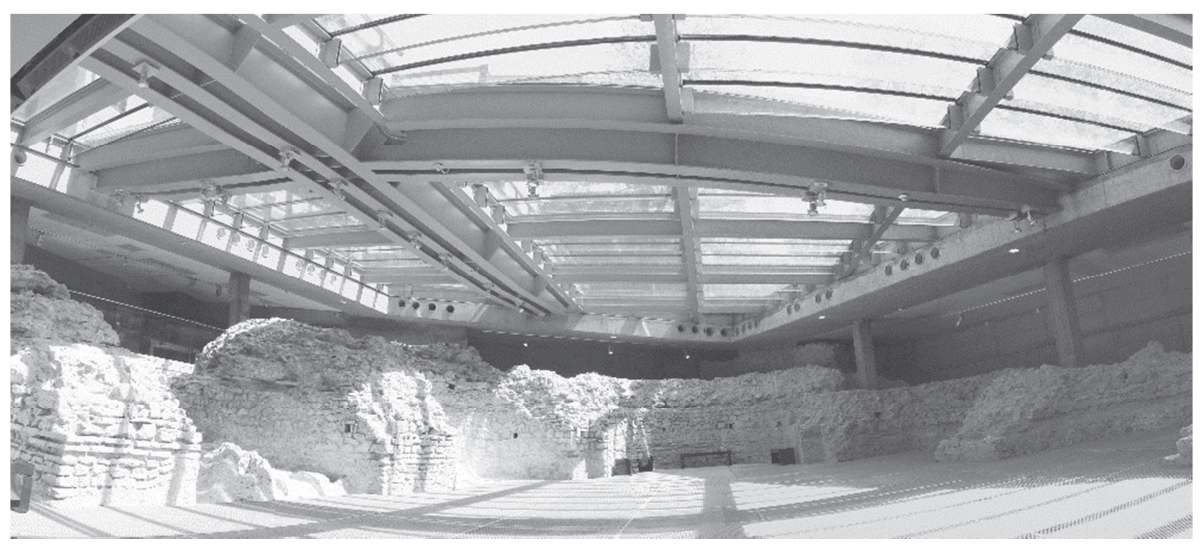

Fig. 3. Main hall in the Cella Septichora

It is a sacred place the mere natural quality of which led him to make statements such as this: 'How could such a seven-apse space be created after all those dull quadratic forms? I can imagine only one answer: the person creating it must have been a true genius.' This recognition of the unique nature of the find made him move away from the position of a passive observer of art. His admiration unfolded in a whole series of ideas, a complete project, and an implementation strategy. He involved various professionals 
and inspired their cooperation: archaeologists, structural engineers and bureaucrats fighting an uphill battle with red tape, just as much as another architect providing congenial support to Bachman's vision: György Stocker 'the Glazier'. As a result, something new was created; something incomparable to anything that we had seen before, something that that incorporates a church, a community space, the proud confidence of high-tech architecture, as well as humble respect for the ancestors. A space that accommodates both sacral and secular events; a space that serves as an exceptional site of remembrance suitable for contemplating on arts, and an impressive stage for an imaginary performance.

Another excellent example at hand from Bachman's oeuvre is the charismatic composition of a pilgrim church to have been built in Croatia, but unfortunately only exists in the form of plans and models (Fig. 4).

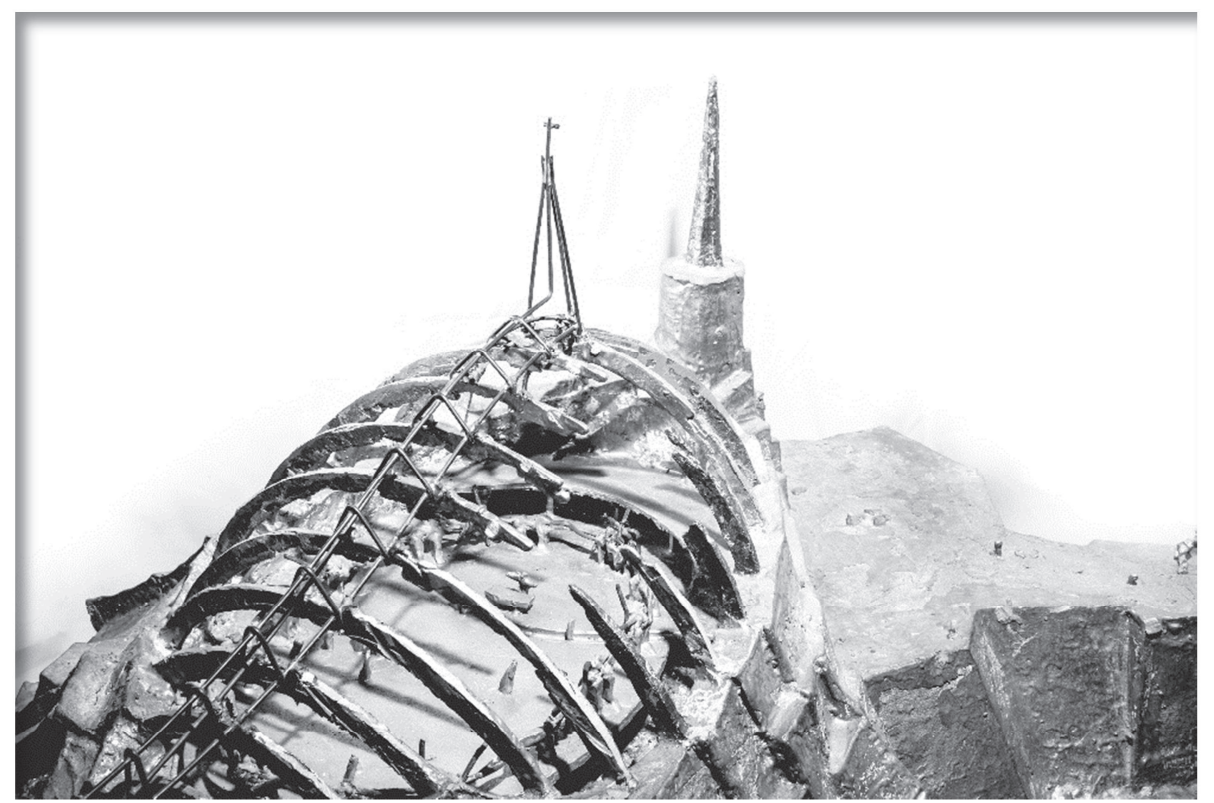

Fig. 4. The composition of a pilgrim church in Croatia

Should the construction have been accomplished in the embrace of the rocks with its golden coloured glass fibre reinforced awning, which was to accommodate fourteen chapels representing the fourteen Stations of the Cross, it would have probably been the most extraordinary, most spectacular and most emotional sacral building in the southcentral-eastern region of Europe. Unfortunately, the plans were not implemented and today one needs to use their imagination to create a view of the rib system of a floating dome sitting on rough, rectangular forms evoking asceticism; the soldered truss system of the lantern tower; the bell tower scraping the low sky and, most especially, the way of the cross, the focus of the liturgy, which represents the crown of thorns symbolizing endless suffering and at the same time the dynamic movements of the Kolo folk dance 
of Hungary's southern neighbours symbolizing rampant joy. 'In fact, I am not sure whether Zoltán is a Catholic, a Calvinist, an Orthodox, a Jew, a Muslim, a Buddhist or maybe an atheist', his friend and artist fellow, the Bosnian writer Tahir Mujcic wrote about him referring to this work of art and added: 'But this is not important anyway... Bachman is a believer. He believes in goodness and peace. And he knows God is one.'

An early Christian building or a church designed to fit into a rocky landscape clearly tells a lot about the visual world view of their creator: the sacral message of time trapped in space. And what makes it extraordinary is that Bachman was able to transfer part of the other-worldly into our own world and that the hidden message of the Science Building complex accomplished in cooperation with his son seems to perfectly rhyme with that of the above mentioned works of art (Fig. 5).

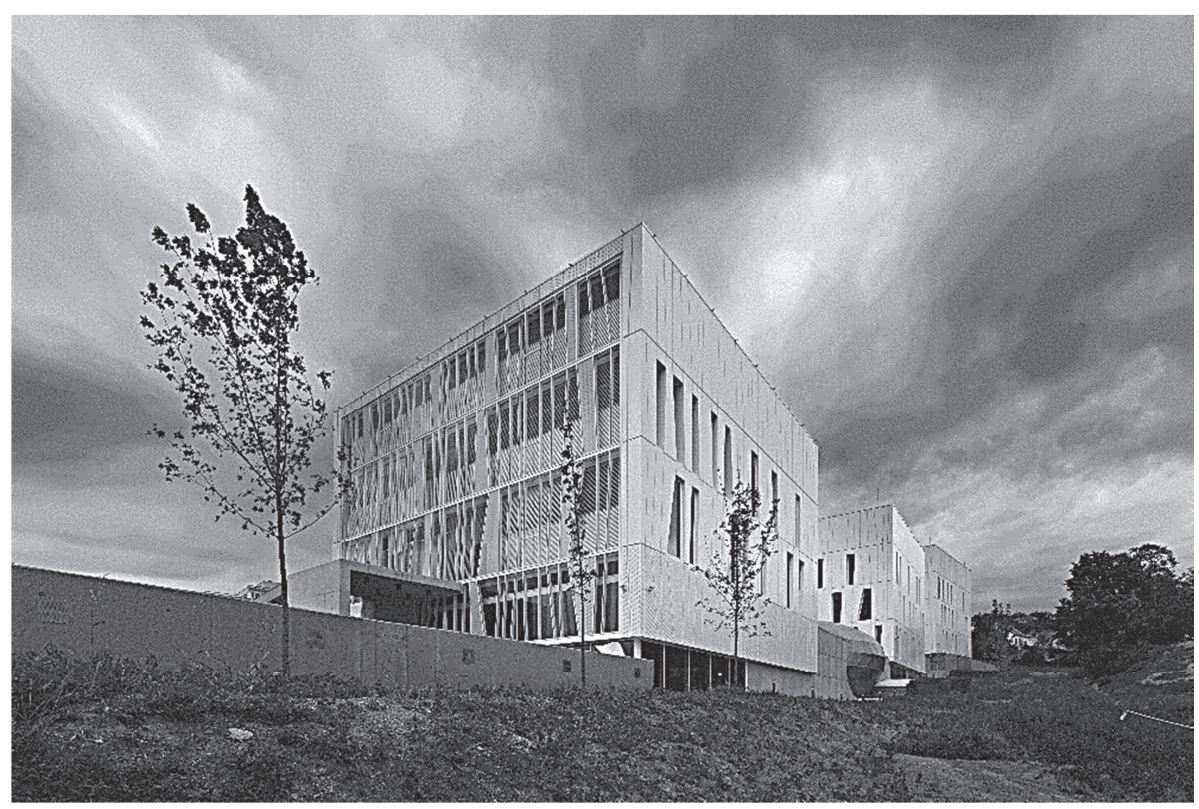

Fig. 5. The Science Building

The stunningly white three cubes of the Science Building with the big shiny 'pebble' lying amidst them offer the kind of ingenuity that defies reason. 'Strange enough, but in the forty years of my career this is the first greenfield investment I am involved in; this is the first time I have the opportunity to design an individual new building on an individual plot', he recalled the emotions he had when he was assigned with the task. 'It actually felt strange not to have all those restrictions I was used to in building construction related to cultural heritage sites.' However, there were more than enough rules to follow in this project as well. If you are to meet the expectations and requirements of medical doctors, biologists, mathematicians and IT experts, you must follow a system of rules just as strict as sacral liturgy with its uncompromising traditions. The mission to be accomplished here was to create an informal atmosphere 
within a highly strict system; to find harmony in a project where the success of the enterprise was subject to finding the appropriate proportion of compromises to be accepted or rejected in terms of everything from the terrain conditions to the materials. This is what you would call 'dancing bound hand and foot' - and this is how, under a lucky star, the great works of applied art are created. What the Science Building is praised most for is its double shell, i.e. the masterly combination of the building engineering system and the building body mutually supporting each other's operation. However, the extra value the artist adds to the project does not actually lie in the structure, be it as unique in Hungary as it is, and not even in the tectonic rhythm of windows. Those are guaranteed by the holder of a diploma of architectus doctus and the many decades of experience, as well as by the special local 'Pannonian' taste that cannot be learned, only born with. What actually became the focus of the visual world view and the epicentre of the message in this project is the Big Pebble bursting into the body of the building. Zoltán Bachman always mastered in stirring the stagnant waters in this present case by adding a visual gesture to a completed building. He was always a master of giving an irrational, spiritual touch to the puritan world of reason, something that directly touches the soul. This glittering, organic shape dropped from the sky into the midst of the cubes is more than an excellent idea. It reveals the actual dimensions of a personality - unique and inimitable as they were. And this is the point where the hidden message of the artist is also revealed: an art work can only be complete if, in addition to being functional, it is also a reflection of the universe, the irrational, the infinite world. If it hides some kind of a secret.

The same secret interweaves the seemingly most profane group of his graphic art heritage, the pastel series of female nudes walking on glass, which are difficult to pigeonhole into a particular genre [2]. The statuesque female bodies shown from the bottom view are both sublime and frivolous at the same time (Fig. 6).

They invoke both the great attraction of his beloved town, Würzburg: the frescoes of the Residence by Tiepolo and the ethology of voyeuristic male eyes together with the apotheosis of the female principle. Mastery and playfulness, wisdom and joy are walking, sliding, writhing and sitting upon the imaginary glass surface, the antecedent of which we have the chance to see among the walls of the internationally acclaimed Pécs Visitor Centre. These skills, adding something special to tangible reality, successfully elevate the physical spectacle to a transcendental, divine level. The brilliant series bears testimony to Bachman's mastery of body contouring, art anatomy and the effects of colour and tonal values. However, what lies behind it is of even greater importance. The beautiful floating bodies, almost always shown from a foreshortened perspective, give the viewer the impression that the border between Heaven and Earth is blurred and life must have been perceived as something really wonderful if the artist was given the chance to cross that line.

As we - his close colleagues, friends and students - came to understand, most of his graphic art works - the nude women mentioned earlier, and especially his profoundly moving Christ paraphrases, the rough pastels of the Havi Hill Cross (Fig. 7), the sheets stretching with passionate tension around Sándor Rétfalvi's Redeemer sculpture on the Tettye Hill, as well as his composition depicting the sublimely dramatic forms of the Pieta in Máriagyűd - were rooted in near-death experiences. 


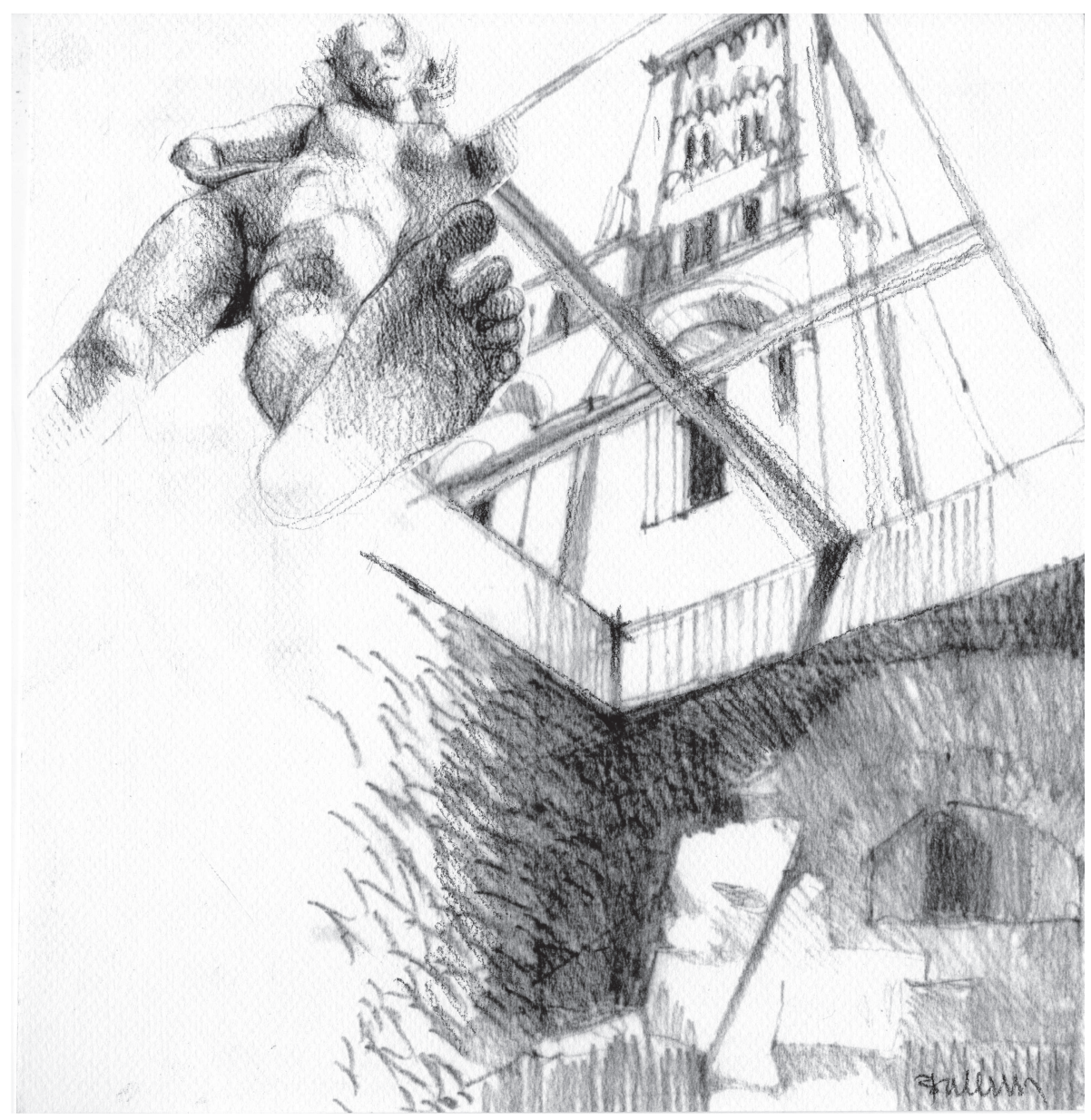

Fig. 6. Graphic

The more he felt the difficult hours approaching, the stronger he clung to the use of graphite, pencil and chalk. As if he was searching for a way to depict the Big Picture that is to be seen by all of us, and that was to be soon seen by him. As if he was trying to get used to the unknown empire which he so humbly served throughout his entire worldly life.

However, he also had profound 'near-life experiences'. And those accounted for the ordinary, warm and informal side of his visual world view. I had the sad privilege of writing his obituary in the faculty news journal and therefore I had it as a task to enumerate his meta-artistic activity, the fruit of which was his earthly empire: the university and especially the doctoral school. I cannot but reiterate my thoughts expressed in that eulogy, my profound memories of first meeting him. 


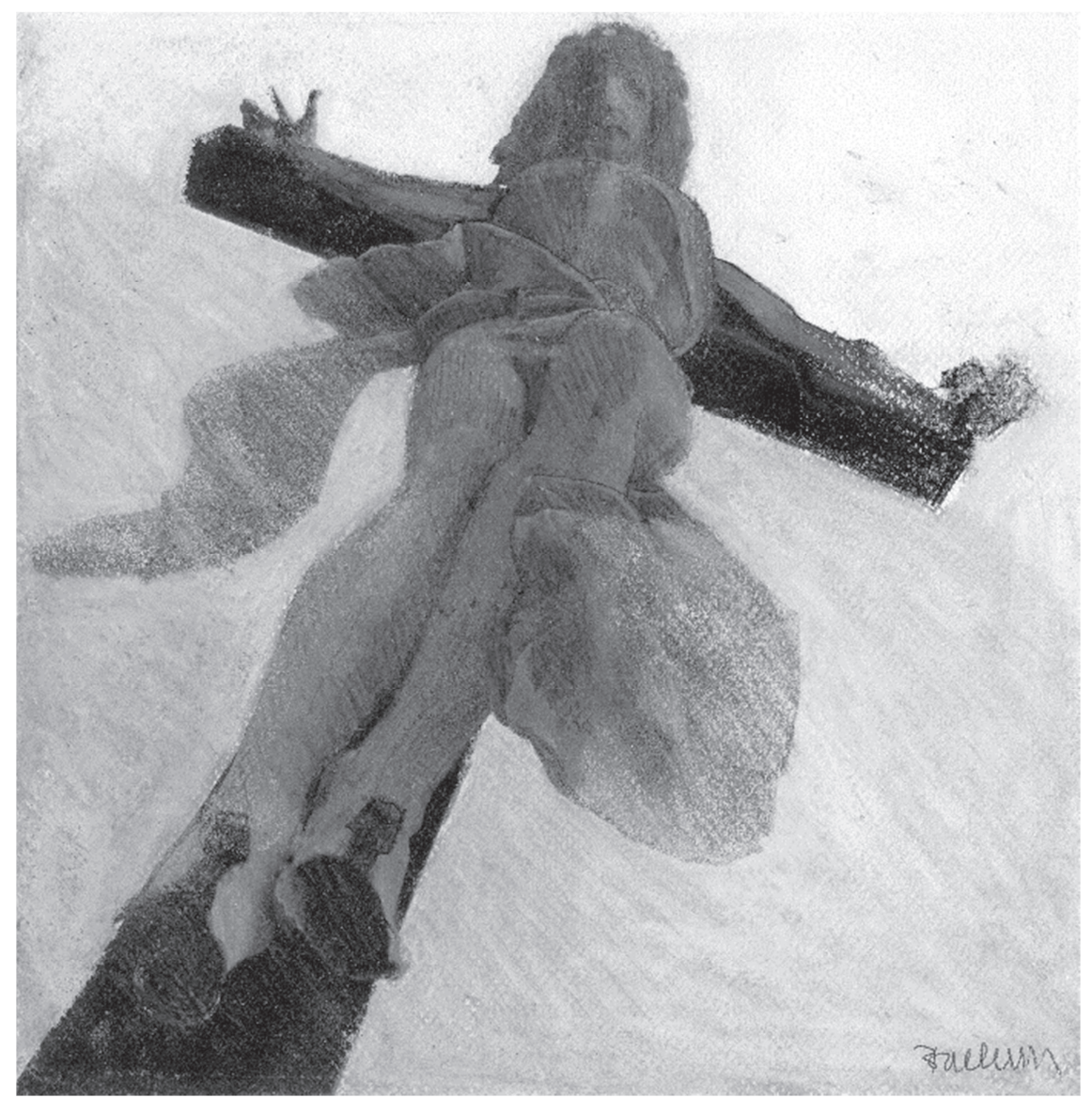

Fig. 7. The Havi Hill Cross

When I entered the two-storey workshop next to the director's office for the first time, I did not yet understand how the system worked (Fig. 8). One of my young colleagues was assembling a cardboard model. Another 'kid' was showing a video installation to a third one who was already dressed in a jacket waiting for the bus to take them to the venue of a conference. The fourth person, the good old bridge engineering professor was studying the sketches of a first-year $\mathrm{PhD}$ student [3]. The fifth one, a tall, blond graduating student was arranging appointments, booking hotel rooms and conference venues - the tasks of an entire department elsewhere. A freshly failed graduate student was trying to gather hope in one of the corners of the workshop. The new assistant professor was searching for a new publication using some slow software in another corner. Zoltán, the unmoved mover was just sitting at the imaginary intersection point of golden ratio space diagonals. He mumbled something from time to time, now he spoke then he was quiet again. He was never loud. He did not need to be. What made things work was freedom as everyone knew their tasks; and since everyone 
knew their tasks, they were all free. This was exactly what an ideally functioning workshop; a bottega looked like in Florence in the 1470s in my imagination.

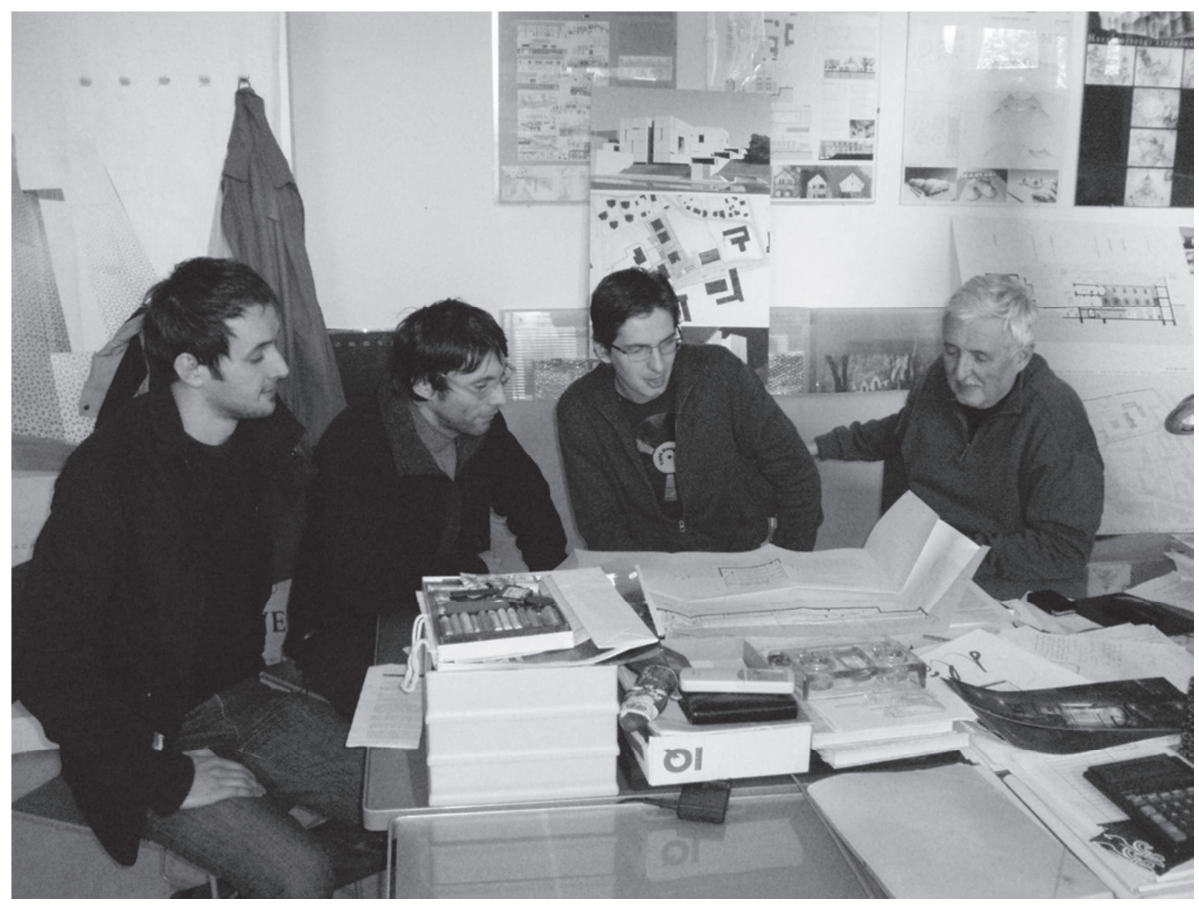

Fig. 8. Prof. Zoltan Bachman with Balint Bachmann, Soma Kistelegdi and Akos Hutter

\section{Conclusion}

Now, back from quoting myself: this is exactly how I imagine a real leader; a leader whose respect is not dependent on orders of merit received or on the ever changing decisions of the bureaucratic world or on any entangled power relations. Although, may I add, these are also important factors to be considered. Nevertheless, the respect he was surrounded by was due to some kind of a mysterious inner power. Someone told me once that a good leader is always ahead of others and never gets tired. And the strongest energy feeding this indefatigability in Zoltán Bachman came from his vision of the world seen in its perfect unity, with the realm of the other world being an integral part of this unity. As far as I could see, he was not afraid of death because he knew he was leaving some kind of a heritage behind. And he actually left a great heritage. 


\section{References}

[1] Bachman Z.,_Bachmann B. (Ed.), Clifford R. A. (Trans.), Bachman Zoltán, Vince kiadó, Budapest, 2010.

[2] Bachman Z., Bachmann B. (Ed.), Graphics, (in Hungarian) Vince Kiadó, Budapest, 2010.

[3] Bachmann B., Bachman Z. (Ed.) Breuer Marcell Doctoral School, (in Hungarian) Vince Kiadó, Budapest, 2012. 